\title{
Simulasi Numerik Aliran Melintasi Backward Facing Step Dengan Penambahan Rectangular Bump
}

\author{
Sulaiman Ali ${ }^{1}$, Luthfi Hakim ${ }^{2}$, Rusman $\mathrm{AR}^{3}$ \\ ${ }^{1}$ Jurusan Teknik Mesin, Fakultas Teknik, Universitas Teuku Umar, Meulaboh \\ ${ }^{2}$ Departemen Teknik Mesin, Institut Teknologi Sepuluh Nopember, Surabaya \\ ${ }^{3}$ Jurusan Teknik Mesin, Fakultas Teknik Universitas Teuku Umar, Meulaboh \\ Email: teungkusulaiman@gmail.com,Luthfihk@gmail.com, rusman@utu.ac.id
}

\begin{abstract}
Abstrak
Rectangular bump merupakan salah satu jenis pengganggu atau turbulator dengan tujuan mengganggu aliran supaya aliran menjadi turbulen lebih awal sebelum daerah recirculaion flow. Penelitian ini dilakukan untuk mendapatkan informasi mengenai fenomena aliran yang melewati backward facing step setelah dilakukan penambahan rectangular bump didepan daerah recirculation. Rectangular bump ditempakan dengan jarakyang berbeda ( $/$ /d = 0,5 dan $s / d=2)$ dengan harapan bisa memprediksi Reattachmen lenght, menghitung nilai Coefficient pressure (Cp) dan Skin friction coefficient (Cf). Penelitian dilakukan secara numerik menggunakan perangkat lunak Computational Fluid Dinamics (CFD) komersial. Dengan memilih berbagai model turbulensi, yaitu model Standard k- (SKE), model Realisable k- (RKE), model Standard $k-\omega(S K W)$ dan model Shear-Stress-Transport (SST) $k$ - $\omega$ (SSTKW).
\end{abstract}

Keywords:, Backward Facing Step, Computational Fluid Dinamics, Reattachment, Rectangular Bump

\section{PENDAHULUAN}

Penelitian tentang aliran yang melintasi Backward facing step telah banyak dilakukan oleh para peneliti, baik secara ekperimen maupun secara simulasi. Secara simulasi telah dilakukan oleh Skovgaard dkk [1] menginvesigasi aliran yang melintasi Backward facing step untuk bilangan Reynolds rendah dengan menggunakan model turbulensi k- model. Sedangkan secara ekperimen dilakukan oleh Restivo [2] untuk bilangan Reynodls 5050. Begitu pula dengan yang dilakukan oleh Peng dkk [3] meprediksi Reattachment lenght dengan membandingkan model turbulensi k- dengan model k- $\omega$.

Paper ini mengevaluasi fenomena aliran yang melewati Backward facing step setelah dilakukan penambahan rectangular bump yang ditempakan sebelum daeah recirculaion. Rectangular bump merupakan salah satu jenis pengganggu atau turbulator dengan tujuan mengganggu aliran supaya aliran menjadi turbulen lebih awal sebelum daerah recirculaion flow. Rectangular bump yang ditempatkan pada jarak tertentu diharapkan mampu meningkatkan turbulensi sehingga memperpendek reattachmen length. Penelitian ekperimen telah dilakukan sebelumnya untuk mengukur Coefficient pressure (CP), Skin friction Coefficient (Cf) profil kecepatan dan vekor kecepatan di daerah recirculation flow penelitian yang dilakukan oleh Driver, Seemiler [4]. Sedangkan Kim dkk [5] membandingkannya antara hasil numerik dengan hasil ekperimen. Kajian numerik dilakukan dengan menggunakan berbagai model turbulensi. 


\section{Jurnal Mekanova \\ Vol 5. No. 2 oktober 2019 \\ ISSN : 2502-0498}

Penelitian ini bertujuan untuk memprediksi reattachment length dengan memvariasi jarak rectangular bump (s/d). Penelitian ini juga mengukur nilai Coefficient pressure $(\mathrm{Cp})$, Skin friction coefficient $(\mathrm{Cf})$ dan menampilkan profil kecepatan dan vekor kecepatan di daerah reattachment length. Dengan memilih berbagai model turbulensi, yaitu model Standard k-

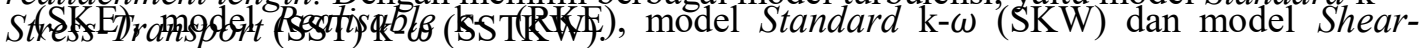

\section{Tahapan Penelitian}

\section{METODE PENELITIAN}

Simulasi ini menggunakan perangkat lunak CFD komersial dengan menggunakan metode diskritisasi Second order upwind. Simulasi dilakukan dengan asusmsi aliran berupa aliran incompressible, steady, viscous, dua dimensi, dan adiabatic. Untuk menganalisa karakteristik aliran yang melintasi Backward facing step terdapat tahapan yang dilakukan, yaitu tahap simulasi CFD. Simulasi CFD pada aliran yang melintasi Backward facing step meliputi tahap Pre-processing, Processing dan Post-processing.

\section{A. Tahap Pre-Processing}

Tahap pre-processing merupakan tahap awal untuk menganalisa pemodelan CFD. Tahap ini terdiri dari pembuatan geometri, meshing, dan penentuan kondisi batas. Tahapan dalam pre-processing menggunakan software GAMBIT 2.4.6.

\section{Meshing dan Kondisi Batas}

Pembuatan mesh elemen hingga (meshing) adalah pembagian model solid menjadi elemenelemen kecil sehingga kondisi batas dan beberapa parameter yang diperlukan dapat diaplikasikan ke dalam elemen-elemen tersebut. Karena keakuratan simulasi bergantung pada grid yang dibuat, sehingga dilakukan grid independent test. Ada empat meshing dengan jumalah faces yang berbeda. Keempat mesh tersebut di evaluasi dengan model turbulensi Standard k- . Pada kecepatan freestream 44.2 m/s. Tabel 1 menunjukkan detil jumlah face dan $\mathrm{y}^{+}$pada variasi mesh.

Tabel 1. Jumlah face dan $\mathrm{y}^{+}$pada kedua variasi mesh.

\begin{tabular}{lllll}
\cline { 1 - 2 } Jenis variasi & Node & Face & $\mathrm{y}^{+}$maximum & $\mathrm{y}^{+}$minimum \\
\cline { 5 - 6 } Mesh A & 13928 & 27577 & 2372 & 0 \\
Mesh B & 26255 & 52114 & 2351 & 0 \\
Mesh C & 36805 & 73164 & 133.4 & 0 \\
Mesh D & 42146 & 83805 & 135.1 & 0 \\
\hline
\end{tabular}

Tabel 2. Grid Independencents test - Coeffcient pressure (Cp)

\begin{tabular}{|l|l|l|}
\hline \multicolumn{2}{|c|}{ Coefficients Pressure (Cp) } \\
\hline $\begin{array}{l}\text { Eksperimental } \\
\text { Driver, Seegmiler }\end{array}$ & 0,1237 & Error \\
\hline & Nilai Prediksi & $21,58 \%$ \\
\hline Mesh A & 0,1504 & \\
\hline
\end{tabular}


Jurnal Mekanova

Vol 5. No. 2 oktober 2019

ISSN : 2502-0498

\begin{tabular}{|l|l|l|}
\hline Mesh B & 0,1497 & $21,02 \%$ \\
\hline Mesh C & 0,1288 & $4,12 \%$ \\
\hline Mesh D & 0,1240 & $0,24 \%$ \\
\hline
\end{tabular}

Dari hasil pada tabel 2, dipilih mesh $\mathrm{C}$ dan D karena nilai errornya lebih kecil dari pada mesh A dan B. Tipe kondisi batas dari model inlet dipilih velocity inlet. Sedangkan outlet dipilih outflow. Dinding atas dan bawah dipilih Wall, kemudian bump didefinisikan sendiri sebagai wall. Gambar 1 dan 2a, 2b secara berurutan menunjukkan geometri dan meshing yang digunakan untuk penelitian ini.

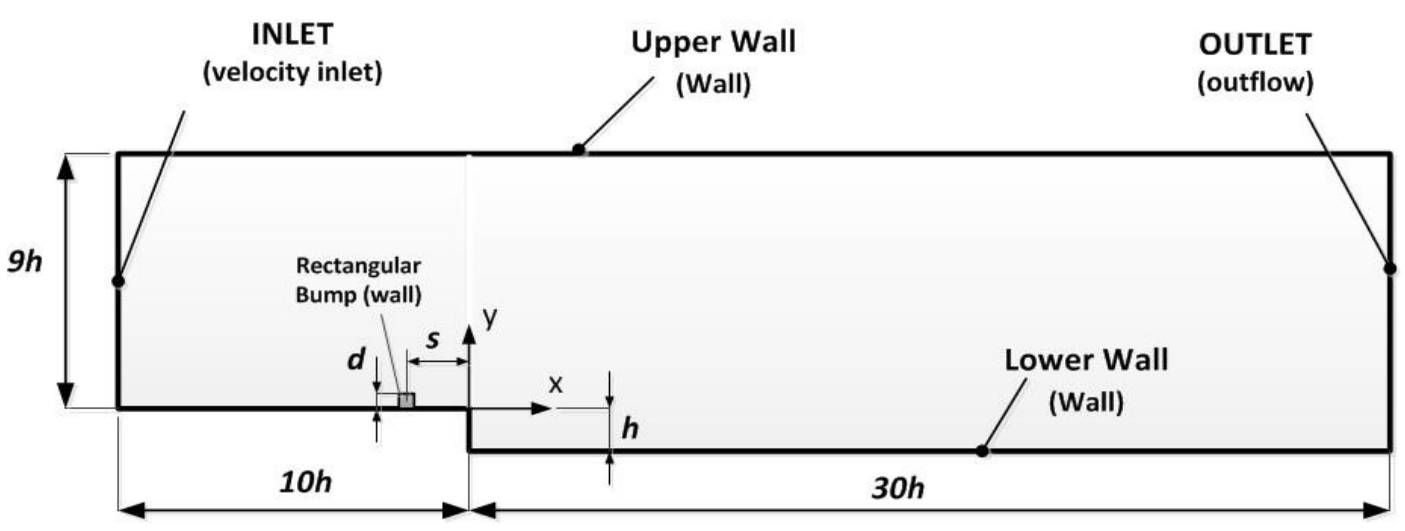

Gambar .1 Geometri Backward facing step dengan penambahan Rectangular bump

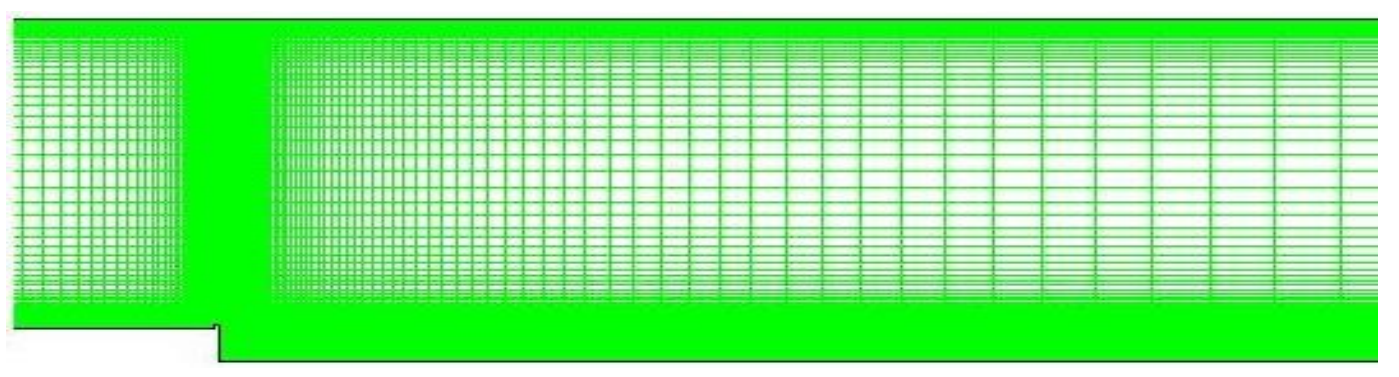

Gambar 2a. Meshing Quadrilateral-map pada Backward facing step pada variasi 1 (s/d = $0.5)$

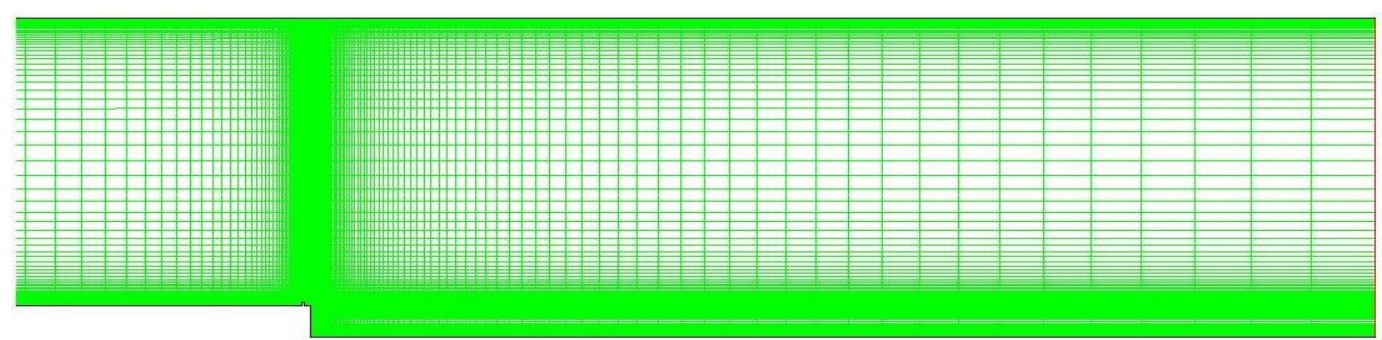

Gambar 2b. Meshing Quadrilateral - map pada Backward facing step pada variasi $2(\mathrm{~s} / \mathrm{d}=$ 2) 


\section{Jurnal Mekanova \\ Vol 5. No. 2 oktober 2019 \\ ISSN : 2502-0498}

\section{B. Tahap Processing}

Processing merupakan langkah kedua dalam melakukan simulasi numerik dengan CFD. Langkah-langkah yang dilakukan meliputi: memilih solver, model turbulensi, sifat material yang digunakan, menentukan kondisi batas, mengatur parameter control solusi, melakukan iterasi dan menyimpan hasil iterasi.

\section{Tahap Post-Processing}

Proses ini merupakan proses akhir dari simulasi. Dimana hasil simulasi berupa data kualitatif dan kuantitatif. Data kualitatif berupa visualisasi aliran dan kontur kecepatan. Data kuantitatif berupa, koefisien gesekan (Cf) dan koefisien tekanan (Cp). Data kuantitatif tersebut akan diolah dengan perangkat lunak Microsoft Excel 2007. Sehingga data kuantitatif tersebut dapat ditampilkan dalam bentuk grafik.

\section{Reattachment length}

\section{HASIL DAN PEMBAHASAN}

Setelah melewati bump kemudian melewati facing step sehingga aliran akan mengalami separasi sehingga terjadi aliran balik (back flow) yang kemudian membentuk aliran sekunder (vortex) didaerah dekat dinding. Hal tersebut diakibatkan oleh pembesaran penampang aliran sehingga kecepaan fluida akan menurun, fluida tidak lagi mampu melawan friksi dan tekanan balik (back pressure) yang berlawanan dengan arah aliran fluida inlet, sehingga aliran fluida akan terseparasi.

Aliran fluida tersebut dapat pulih kembali, tetapi butuh panjang relaxasi (reattachment length) dan titik awal pulihnya aliran fluida ini disebut reattachment point. Prediksi panjang reattachment ditunjukkan pada tabel 2 . sebagai berikut.

Tabel 2. Panjang Reattachment untuk model turbulensi setelah penambahan bump

\begin{tabular}{lccc}
\hline $\begin{array}{l}\text { Model } \\
\text { Turbulensi }\end{array}$ & $\begin{array}{l}\text { Panjang reattachment } \\
\text { untuk variasi } 1\end{array}$ & $\begin{array}{l}\text { Panjang reattachment } \\
\text { untuk variasi } 2\end{array}$ & $\begin{array}{l}\text { Simulasi tanpa } \\
\text { bump oleh Kim } \\
\text { dkk [5] }\end{array}$ \\
\hline SKE & $4.9-5.1$ & $6.9-7.1$ & $4.9-5.1$ \\
RKE & $5.7-5.9$ & $8.4-8.6$ & $5.7-5.9$ \\
SKW & $6.6-6.9$ & $9.2-9.4$ & $6.7-6.9$ \\
SST & $7.2-7.4$ & $8.4-8.6$ & $6.1-6.3$ \\
\hline
\end{tabular}

Reattachment point dapat ditentukan dengan cara mencari vektor kecepatan yang berharga nol pada sejumlah node yang telah di sortir. Apabila node yang telah disortir tidak menunjukkan vektor kecepatan yang berhaga nol, maka titik reattachment length dapat diprediksi dengan menginterpolasi antara dua node yang berharga negatif dan positif. Untuk menvalidasi, simulasi yang telah dilakukan dibandingkan dengan simulasi yang dilakukan oleh Kim dkk [5].

Sesui dengan percobaan yang telah dilakukan oleh Kim dkk [5], hasil dari simulai menunjukkan bahwa ada nilai yang sama untuk beberapa model turbulensi pada variasi 1 $(\mathrm{s} / \mathrm{d}=0.5)$, dimana pada variasi 1 bump diletakkan tepat sebelum adanya perbesaran penampang. Nilai panjang reattachment yang sama yaiu pada model SKE, RKE, sedangkan pada model, SKW dan SST memiliki nilai yang berbeda. Jika dibandingkan dengan variasi $2(\mathrm{~s} / \mathrm{d}=2)$, panjang Reattachment memiliki nilai yang lebih besar untuk semua model turbulensi. Artimya, dengan adanya penambahan bump yang semakin jauh dengan jarak dari facing step akan memperpanjang reattachment. 


\section{Jurnal Mekanova}

Vol 5. No. 2 oktober 2019

ISSN : 2502-0498

\section{Koefisien gesekan dan koefisien tekanan}

Gambar 3a. dan 3b. menunjukkan perbandingan nilai Coefficient pressure (Cp) dan Skin friction coefficient $(\mathrm{Cf})$ didaerah Bottom wall untuk variasi 1 pada beberapa model turbulensi dengan percobaan yang dilakukan oleh Driver, Seegmiller [4]. Gafrik tersebut menunjukkan trend line yang sama antara simulasi dan percobaan. Dengan penambahan Rectangular Bump akan memperbesar nilai maksimum baik pada Coefficients Pressure (Cp) dan Skin friction coefficient (Cf) pada setiap model turbulensi. Penambahan nilai Coefficients Pressure (Cp) dan Skin friction coefficient (Cf) untuk masing-masing model turbulensi secara berurutan sekitar tujuh kali lipat dan tiga kali lipatnya.

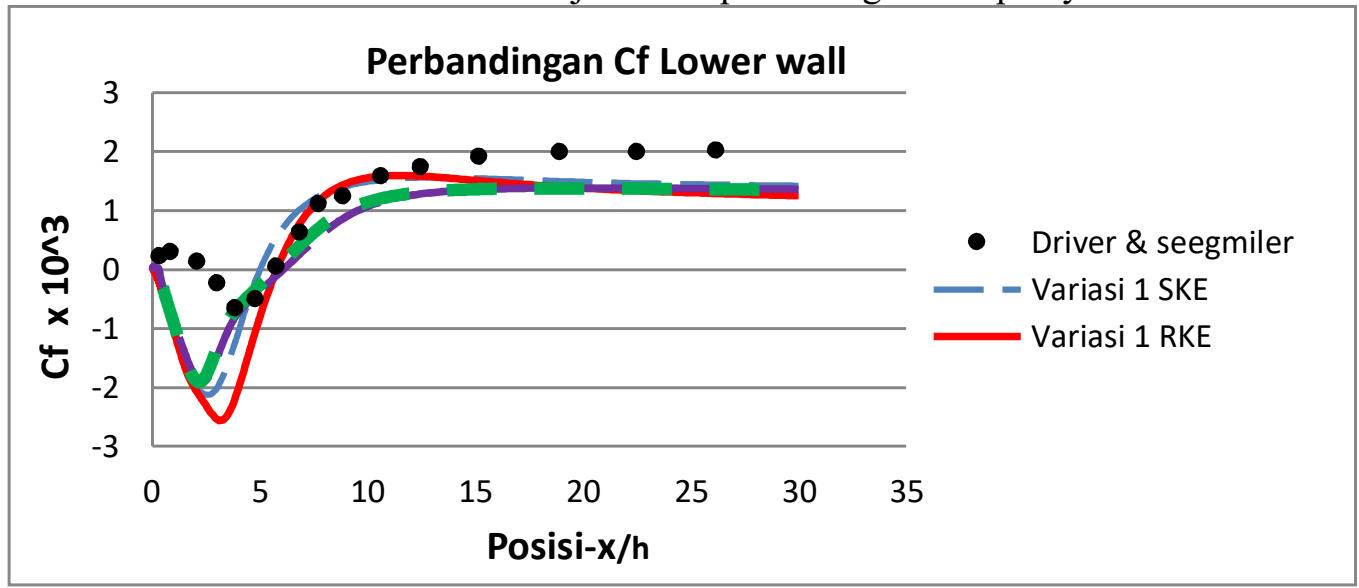

Gambar 3a. Perbandingan Skin friction coefficient (Cf) untuk variasi 1 pada beberapa model turbulensi

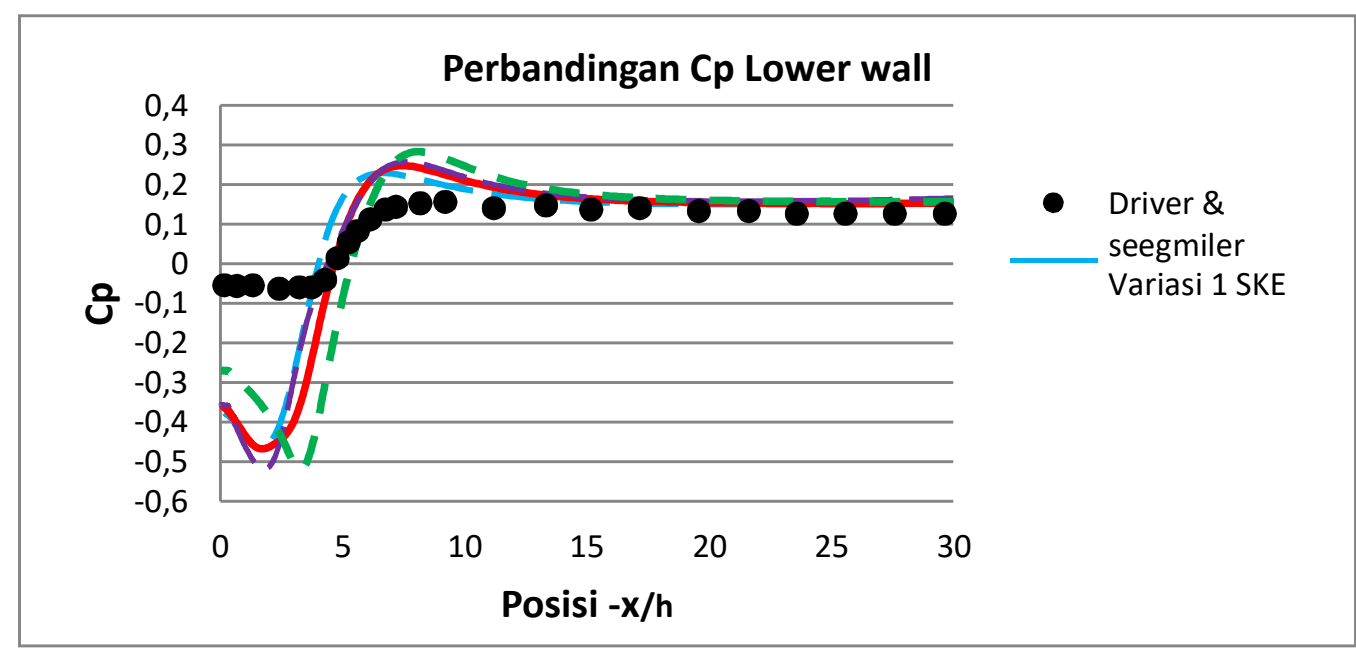

Gambar 3b. Perbandingan Coefficients Pressure (Cp) untuk variasi 1 pada beberapa model turbulensi

Gambar 4a. dan 4b. menunjukkan perbandingan nilai Skin friction coefficient $\left(\mathrm{C}_{\mathrm{f}}\right)$ dan Coefficients pressure $(\mathrm{Cp})$ didaerah bottom wall untuk variasi 2. Gafrik tersebut menunjukkan trend line yang sama antara simulasi dan percobaan. Dengan penambahan Rectangular Bump akan memperbesar nilai maksimum baik pada Coefficients pressure (Cp) dan Skin friction coefficient (Cf) pada setiap model turbulensi. Penambahan nilai 
Coefficients pressure (Cp) dan Skin friction coefficient (Cf) untuk masing-masing model turbulensi secara berurutan empat kali lipat dan satu kali lipatnya.

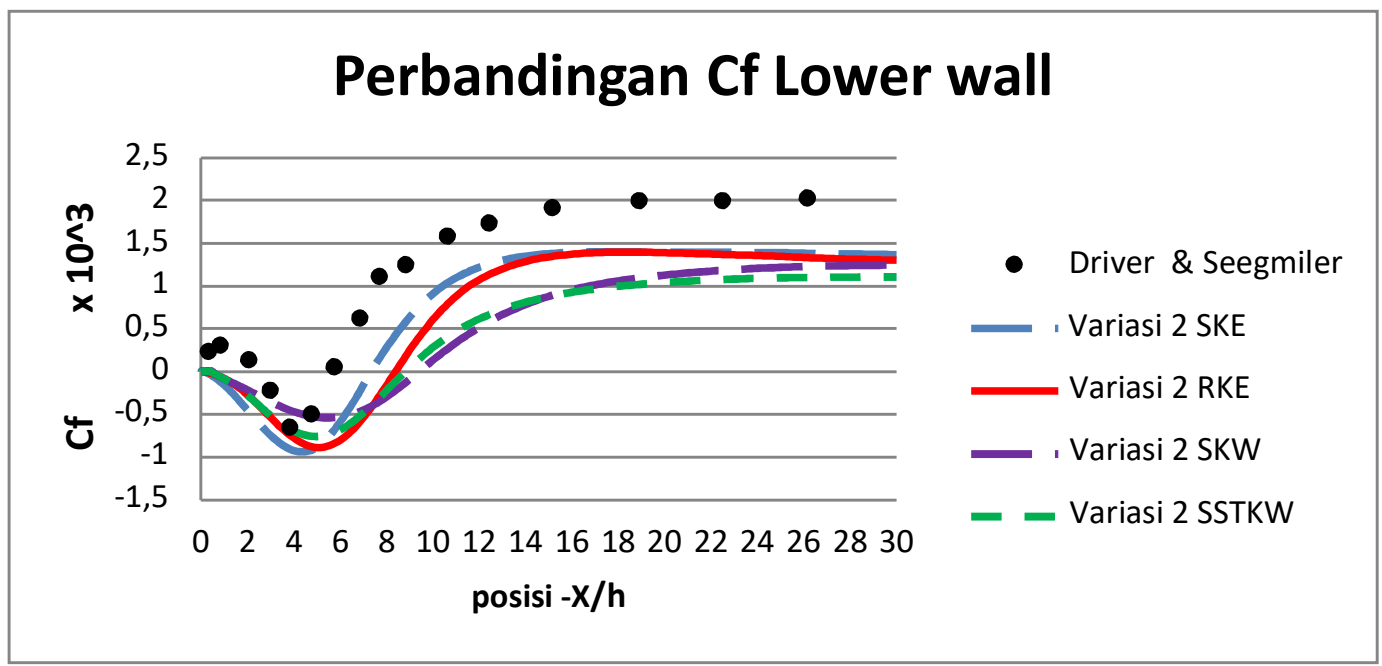

Gambar 4a. Perbandingan Skin friction coefficient (Cf) untuk variasi 2 pada beberapa model turbulensi.

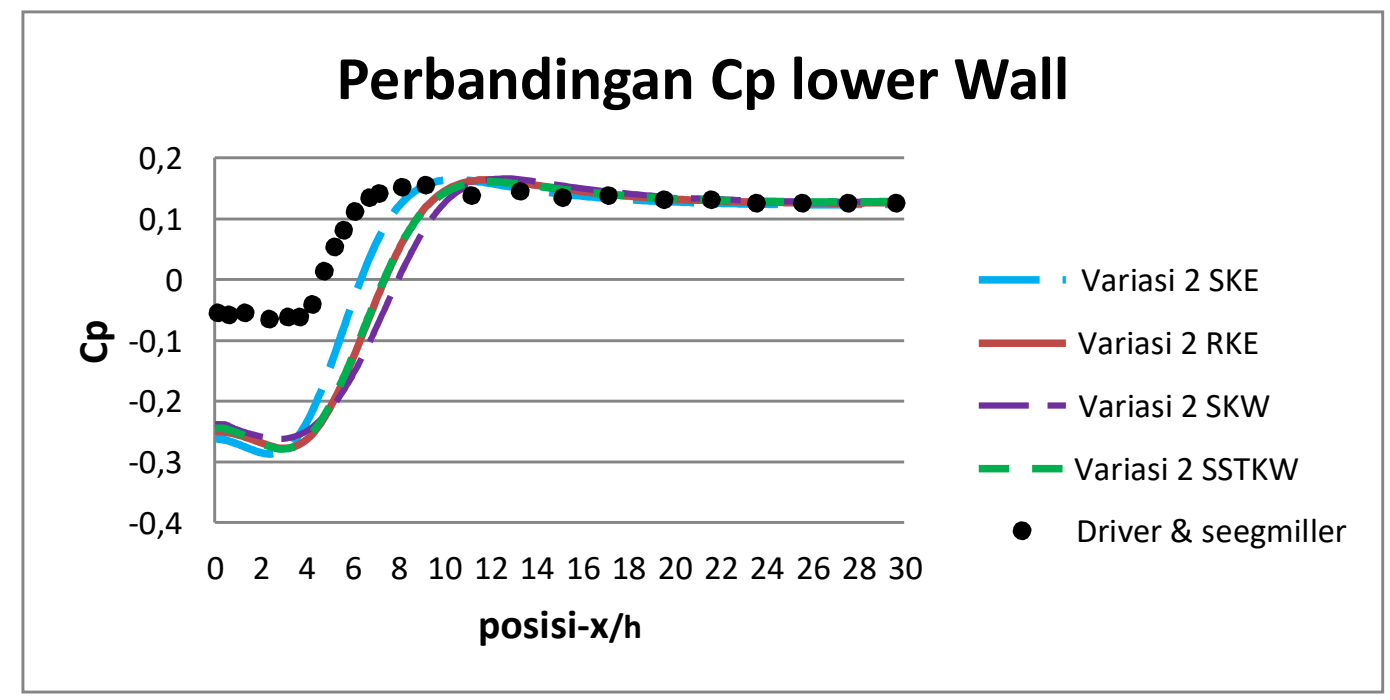

Gambar 4b. Perbandingan Coefficients pressure (Cp) untuk variasi 2 pada beberapa model turbulensi.

\section{Profil kecepatan dan Vektor Kecepatan}

Kontur kecepatan yang menunjukkan terjadinya titik reattachment length terlihat pada Gambar 5. Dimana nilai vekor kecepatannya sama dengan nol. Gambar tersebut menunjukkan kecepatan pathlines dan vector kecepatan yang menunjukkan adanya aliran sekunder pada daerah recirculation. Nilai tekanan pada daerah tersebut berharga negative, sedangkan pada daerah setelah reattachment point bernilai positif dan cenderung konstan. Untuk variasi 2 reactaehmen length lebih panjang dari pada variasi 1. 


\section{Jurnal Mekanova}

Vol 5. No. 2 oktober 2019

ISSN : 2502-0498

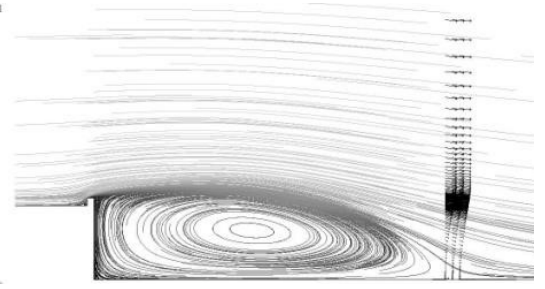

a. SKE

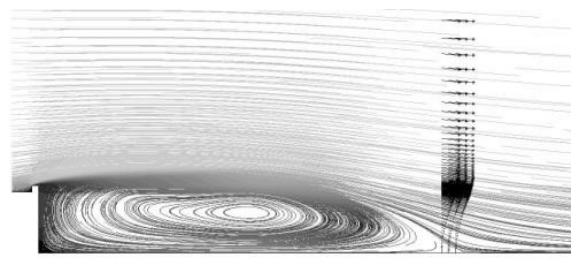

b. RKE

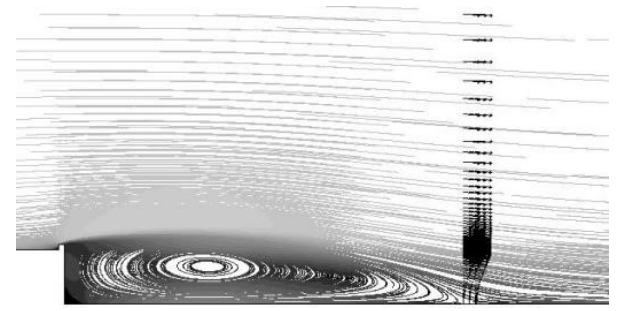

c. SKW

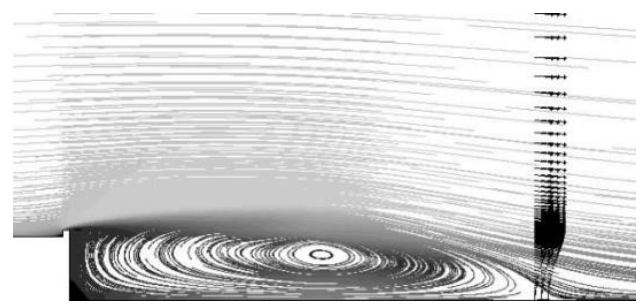

d. SST

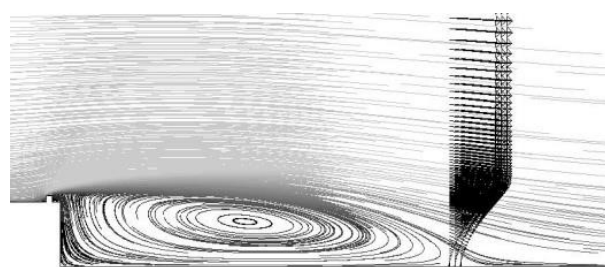

e. SKE

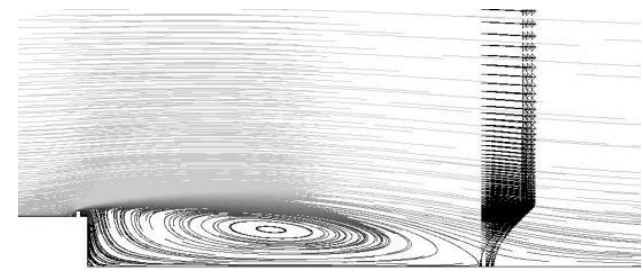

f. RKE

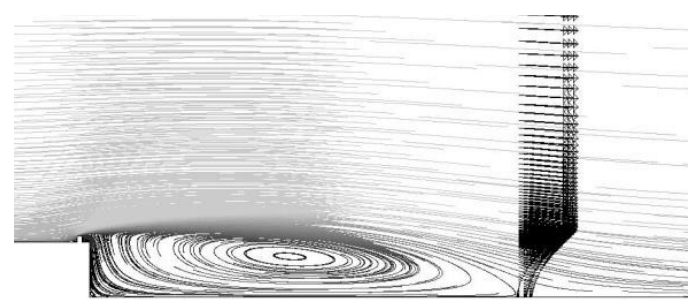

g. SKW

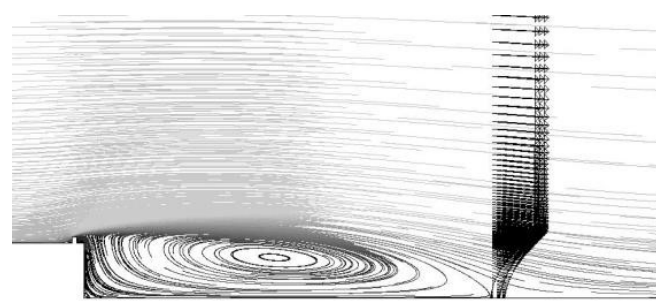

h. SST

Gambar 5. a, b, c, d. Visualisasi kecepatan pathline dan vektor kecepatan pada titik reattachment untuk variasi $1(\mathrm{~s} / \mathrm{d}=0.5)$. e, $\mathrm{f}, \mathrm{g}, \mathrm{h}$. Visualisasi kecepatan pathline vektor kecepatan pada titik reattachment untuk variasi $2(\mathrm{~s} / \mathrm{d}=2)$

\section{KESIMPULAN}

Berdasarkan uraian diatas dengan menampilkan data kuantitatif berupa nilai Coefficients pressure (Cp) dan Skin friction coefficient (Cf) serta data kuantiatif berupa visualisasi kecepatan pathline dan vektor kecepatan menambah informasi mengenai fenomena aliran yang melintasi Backward facing step, sehingga dapat diambil kesimpulan sebagai berikut.

1. Dengan penambahan Rectangular bump yang ditempakan sebelum daerah Recirculation menjadikan Reattachment length lebih panjang, semakin jauh penempatan Rectangular bump dari daerah recirculaion semakin panjang Reattachment length .

2. Nilai maksimum Coeffiecient pressure (Cp) dan Skin friction coeffiecient (Cf) untuk 
Jurnal Mekanova

Vol 5. No. 2 oktober 2019

ISSN : 2502-0498

variasi ke1 lebih besar dari pada variasi ke 2 . 


\section{DAFTAR PUSTAKA}

[1] Skovgaard, M, Nielsen, Peter Vilhelm, (1991), "Numerical Investigation of Transitional Flow over a Backward Facing Step Using a Low", Aalborg: Dept. of Building Technology and Structural Engineering. Indoor Environmental Technology, No. 22, Vol. R9150

[2] Restivo. A. M. 0, (1979), "Turbulent flow in ventilated rooms", Imp. Coll. of Science and Tech, Mech Eng. Dept. Ph.D. Thesis

[3] Peng Shia-Hui, (1996), "The Two-Equation Turbulence k- $\omega$ Model Applied to Recirculating Ventilation Flows", Department of Thermo-and Fluid Dynamics.

[4] Driver, D. M, Seegmiler, H. L, (1985), "Backward facing step with inclined opposite wall experiments"

[5] J.Y.Kim, Afshin J. Ghajar, Clement Tang, (2005), "Comparison of near wall treatment methods for high Reynolds Number backward facing step flow", School of Mechanical and Aerospace Engineering, Oklahoma State University, Stillwater, 74078 